Manen, J.G. van, Bindels, P.J.E., Ijzermans, C.J>, Zee, J.S. van der, Bottema, B.J.A.M., Schadé, E.

Prevalence of comorbidity in patients with a chronic airway obstruction and controls over the age of 40 .

Journal of Clinical Epidemiology: 54, 2001, nr. 3, p. 287-293

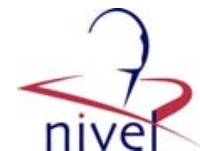

\begin{tabular}{|l|l|}
\hline Postprint Version & 1.0 \\
Journal website & $\underline{\text { http://www.sciencedirect.com/science/journal/08954356 }}$ \\
\hline Pubmed link & $\begin{array}{l}\text { http://www.ncbi.nlm.nih.gov/entrez/query.fcgi?db=pubmed\&cmd=Retrieve\&dop } \\
\text { t=AbstractPlus\&list uids=11223326\&query hl=5\&itool=pubmed docsum }\end{array}$ \\
\hline DOI & $\underline{\underline{10.1016 / \text { S0895-4356(01)00346-8 }}}$ \\
\hline
\end{tabular}

\title{
Prevalence of comorbidity in patients with a chronic airway obstruction and controls over the age of 40
}

\author{
J.G. VAN MANEN ${ }^{\text {A }}{ }^{*}$, P.J.E. BINDELS ${ }^{\text {A }}$, C.J. IJZERMANS ${ }^{\text {A }}$, J.S. VAN DER ZEE ${ }^{\text {B }}$, B.J.A.M. BOTTEMA ${ }^{\text {C }}$, \\ E. SCHADÉ
}

${ }^{a}$ Department of General Practice, Division of Public Health, Academic Medical Center-University of Amsterdam, Amsterdam, The Netherlands

${ }^{\mathrm{b}}$ Department of Pulmonology, Academic Medical Center-University of Amsterdam, Amsterdam, The Netherlands

${ }^{\mathrm{c}}$ Department of General Practice and Social Medicine, University of Nijmegen, Nijmegen, The Netherlands

* Corresponding author. Tel.: + 31-20-5663607; fax: + 31-20-566- 91-86. E-mail address :

j.g.vanmanen@amc.uva.nl.

\begin{abstract}
The goal of this study is to determine the prevalence of 23 common diseases in subjects with a chronic airway obstruction and in controls. All subjects with a known diagnosis by their general practitioner of asthma or chronic obstructive pulmonary disease (COPD), and who were 40 years and older were selected $(n=1145)$. Subjects who were willing to participate $(n=591)$ and who appeared to have an irreversible airway obstruction $(n=$ 290) were included. To recruit controls, a random sample was taken of 676 individuals who were 40 years and older and who were not diagnosed as having asthma or COPD by their general practitioner. Of these 676 individuals 421 were willing to participate. The presence of diseases was determined by using a questionnaire. One hundred and ninetyfour subjects (73\%) and 229 controls $(63 \%)$ were shown to be suffering from one or more (other) diseases. In both groups, locomotive diseases, high blood pressure, insomnia and heart disease were most common. Locomotive diseases, insomnia, sinusitis, migraine, depression, stomach or duodenal ulcers and cancer were significantly more common in the subject group than in the control group. For both clinical and research purposes, it is important to consider the presence of diseases in patients with a chronic airway obstruction.
\end{abstract}

\section{INTRODUCTION}

Comorbidity may frequently occur in patients with a chronic airway obstruction who are over 40 years old. While this group mainly consists of chronic obstructive pulmonary disease (COPD) patients, most will have a history of heavy smoking. Both smoking and older age are considered risk factors for the occurrence of diseases. In addition, a chronic airway obstruction may in itself be a risk factor for other diseases, as it may result in complications such as heart failure.

Determining the presence of a combination of diseases is important for the clinical practice. First, it influences the quality of life of the patient [1,2], which results in an increased need for health care [3]. Second, diagnosis, treatment and prognosis will be influenced by the occurrence of diseases other than chronic airway obstructions. 
Manen, J.G. van, Bindels, P.J.E., Ijzermans, C.J>, Zee, J.S. van der, Bottema, B.J.A.M., Schadé, E.

Prevalence of comorbidity in patients with a chronic airway obstruction and controls over the age of 40 .

Journal of Clinical Epidemiology: 54, 2001, nr. 3, p. 287-293

Comorbidity is also an important methodological issue in clinical trials and in studies on healthrelated quality of life. Most of these studies exclude patients with comorbidities. If comorbidity is frequently seen in patients with a chronic airway obstruction, the external validity of these studies may to a large extent be limited. Furthermore, studies in which patients with comorbidity are included and compared with controls may encounter a confounding effect if the comorbidities turn out to be more common among the patient group than among the control group.

For both clinical and research purposes it is thus important to consider the presence of other diseases in patients suffering from a chronic airway obstruction. Nevertheless, it is unclear which diseases should be our main concern as there is only limited information on the frequency and kind of diseases in this patient group. Also, it is unclear which diseases are more common among patients with a chronic airway obstruction than among controls. Only a few diseases have thus far been described in the studies that we found [2,4-6]. Our study therefore determines the prevalence of 23 common diseases in patients with a chronic airway obstruction and in controls.

\section{METHODS}

\subsection{Selection of subjects with a chronic airway obstruction}

Twenty-eight general practices from urban and suburban regions in the western part of the Netherlands participated in this study. These practices covered almost 55,000 patients at the time of study. Selection of participants was carried out in three consecutive steps. First, all subjects who were registered with a diagnosis of asthma or COPD in their general practice and who were at least 40 years old were selected at one day in each practice. The 28 practices were visited between October 1996 and June $1997(n=1236)$.

Second, the general practitioners were then asked to exclude subjects who met the following criteria: poor cognitive functioning $(n=35)$, a poor mastering of the Dutch language $(n=29)$ and presence of an end-stage disease $(n=27)$. Third, all remaining eligible subjects $(n=1145)$ who were willing to participate underwent a lung function test and filled in a questionnaire between December 1996 and December 1997 ( $n=591$, response is 52\%). Lung function data and questionnaire data were obtained on the same day.

Only subjects with a $\mathrm{FEV}_{1} / \mathrm{VC}$-ratio below the reference ratio minus $1.64 \mathrm{X}$ standard deviation before and after inhalation of $400 \mu \mathrm{g}$ salbutamol were included $(n=290)$. This way only subjects with a chronic obstruction of the airways were selected.

\subsection{Selection of the control group}

In November 1997, a random selection of 676 individuals was made from patients in 13 general practices who were not registered with a diagnosis of asthma or COPD and who were 40 years of age or older. These 13 practices were part of, and representative of, the 28 practices from which the subjects were selected. The sample was stratified: 178 controls between the age of 40 and 60 were selected and 498 controls of 60 years old or older. This was done because of an over-representation of subjects older than 60 years compared to the control population from which the selection was made. The general practitioners were again asked to exclude controls with poor cognitive functioning $(n=$ $30)$, a poor mastering of the Dutch language $(n=7)$ and with an end-stage disease $(n=2)$ from the total sample of 676 individuals. Additionally, all controls with self-reported asthma or COPD were excluded $(n=24)$. Of the remaining eligible controls, 421 were willing to participate and filled in the questionnaire between April and July 1998 (response was 69\%).

\subsection{Data collection procedures}

To determine the presence of comorbid diseases, all participants were asked to complete a questionnaire on 23 diseases. This questionnaire was developed by Statistics Netherlands and is broadly used in demographic studies in the Netherlands [7]. Diseases included in the questionnaire have a prevalence of more than $2 \%$ and are long-lasting by nature. With this questionnaire, participants were asked whether they were suffering from one or more of the 23 listed diseases at that moment. The diseases were described in a way that was easy to understand for the participants; for example, the term "high blood pressure" was used instead of "hypertension." If participants indicated 
Manen, J.G. van, Bindels, P.J.E., Ijzermans, C.J>, Zee, J.S. van der, Bottema, B.J.A.M., Schadé, E.

Prevalence of comorbidity in patients with a chronic airway obstruction and controls over the age of 40 .

Journal of Clinical Epidemiology: 54, 2001, nr. 3, p. 287-293

that a particular disease was present, they were then asked whether they had used medication and whether they had visited a doctor for this disease in the past 12 months. The following diseases were listed: locomotive diseases (rheumatoid arthritis, arthrosis, slipped disc, disorder of the back for $>3$ months), hypertension, insomnia, serious heart diseases or myocardial infarction, sinusitis, migraine, depression, dizziness with falling, ulcer stomach/duodenum, cancer, atherosclerosis, thyroid diseases, diabetes, serious intestinal diseases for $>3$ months, serious skin diseases, gall bladder diseases, stroke, chronic cystitis, kidney stones, thrombosis, epilepsy, liver diseases and renal diseases. In addition, questions on demographic factors (gender, age, education, health insurance, living situation) and smoking were asked.

\subsection{Analysis}

In the questionnaire all participants were asked about the highest level of education they had received (six levels). The percentages of participants with a high and a low level of education were then calculated. We defined a lower level of education as primary school, lower vocational training and school for lower general secondary education. A high educational level was defined as pre-university education, high vocational training and university. From the data on smoking obtained with the questionnaire, the percentages of smokers, past smokers and never smokers were calculated. A past smoker was defined as someone who had stopped smoking for more than 5 years. A smoker was defined as a current smoker or as someone who had stopped smoking for less than 5 years. The number of diseases $(0, \geq 1$ and $0,1-2,3-4, \geq 5)$ was calculated only for those individuals who had filled in all questions on the presence of diseases.

Chi-square tests were carried out to test whether the prevalence of diseases differed between the subjects and the controls. P-values of less than 0.05 were considered significant. Logistic regression was carried out to adjust for potential confounders. In the logistic regression models the existence of a specific disease or the number $(0, \geq 1)$ of diseases present was the dependent variable. The independent variable of interest in this study was whether the respondent belonged to the subject group or to the control group. This way we could identify specific diseases that are more often seen in subjects with a chronic airway obstruction. All analyses were carried out using SPSS 8.0.2 for Windows.

\section{RESULTS}

\subsection{Inclusion}

Of the 1145 subjects with a known diagnosis of asthma or COPD, 591 were willing to participate (52\%). Of these participants in the subject group $290(49 \%)$ were found to have a persistent airway obstruction and were included in the analysis. Subjects without an airway obstruction before or after inhalation of salbutamol were thus excluded. The control group consisted of 421 participants who had filled in and returned the questionnaire. In the subject group the percentage of men among nonparticipants was 19\% lower than among participants, but no difference in age was found. In the control group there were no significant differences in age and gender between non-participants and participants.

\subsection{Characteristics of the research groups}

In Table 1, the general characteristics of the two groups are presented. In both groups the mean age was 66 years, and one-quarter of the individuals were living alone. The percentages of men, of individuals with a low educational level and of individuals with Dutch National Health Service insurance were significantly higher in the subject group than in the control group. More than half of the patients $(51.4 \%)$ had a mild airway obstruction ( $\mathrm{FEV}_{1} \%$ pred $\left.>70 \%\right)$ and $21.7 \%$ had a serious airway obstruction ( $\mathrm{FEV}_{1} \%$ pred $<50 \%$ ).

\subsection{Prevalence of diseases in the subject group and the control group}

The majority of individuals in each of the two groups reported one or more diseases $(73 \%$ subjects and $63 \%$ controls) (Table 2). If only the diseases are taken into account for which the participant used medication or contacted a doctor in the past 12 months, the prevalence of diseases was $11 \%$ lower in the subject group (62\%) and $12 \%$ lower in the control group (51\%). In both cases the prevalence of 
Manen, J.G. van, Bindels, P.J.E., Ijzermans, C.J>, Zee, J.S. van der, Bottema, B.J.A.M., Schadé, E.

Prevalence of comorbidity in patients with a chronic airway obstruction and controls over the age of 40 .

Journal of Clinical Epidemiology: 54, 2001, nr. 3, p. 287-293

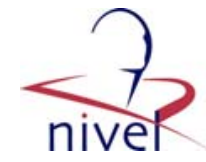

diseases $(\geq 1)$ was significantly higher in the subject group than in the control group. In both groups half of the participants had one to two (other) diseases.

A logistic regression analysis was performed to adjust for differences in gender, education and insurance between the subject group and the control group. As the mean age was about the same in both groups (65.8 and 65.9), we did not adjust for age. The adjusted odds ratio was 1.60 (95\% CI 1.10-2.33), which indicated that the risk of having a disease was about one and one-half times higher in the subject group. When the analysis for diseases for which subjects used medication or contacted a doctor was performed, the adjusted odds ratio was 1.56 (95\% CI 1.10-2.20).

In Table 3 the prevalence of the 23 diseases in both the subject and the control group are shown. In both groups, locomotive diseases, high blood pressure, insomnia and heart disease were most frequently present. There were significant differences in the prevalence of locomotive diseases, insomnia, stomach and duodenal ulcers, migraine, sinusitis, depression, cancer and atherosclerosis between the two groups. The largest difference was $9.9 \%$ for sinusitis, the smallest difference was $3.7 \%$ for cancer.

Again, logistic regression analyses were carried out to adjust for differences in gender, education and insurance between the subject group and the control group (age was not adjusted for, as the mean age did not differ between the two groups). The adjusted odds ratios in the logistic regression models were significant for locomotive diseases (OR 1.55), insomnia (OR 1.65), stomach and duodenal ulcers (OR 7.33), migraine (OR 3.13), sinusitis (OR 6.08), depression (OR 2.10) and cancer (OR 2.47), indicating a higher risk of the disease in the subject group. While the univariate analysis showed a significant difference in the prevalence of atherosclerosis between the subject group and the control group, this was not the case after adjustment.

\subsection{Prevalence of diseases in subgroups of subjects with a chronic airway obstruction}

As can be seen in Table 4, the prevalence of one or more diseases increases with age, but is independent of gender, lung function, and smoking history. The same results were obtained for the number of comorbid diseases. The prevalence of locomotive diseases, insomnia and migraine was more common among female subjects $(48.1 \%, 23.3 \%$ and $16.3 \%$, respectively) than among male subjects $(29.3 \%, 14.0 \%$ and $6.5 \%$, respectively). The opposite was true for heart disease, which was more common among male subjects. Heart disease and high blood pressure occurred significantly more often in subjects older than 70 , while the prevalence of sinusitis, migraine and depression was significantly higher in subjects younger than 55 . The prevalence of sinusitis and depression were significantly higher in subjects with a mild airway obstruction than in subjects with a moderate-tosevere airway obstruction.

\section{DISCUSSION}

In this study we determined the prevalence of 23 diseases in a subject group with a chronic airway obstruction and a control group, both over 40 years of age. We found that the majority of subjects was also suffering from one or more other diseases, and that the prevalence of these comorbidities increased with age. The prevalence of comorbidities was $10-12 \%$ higher in the subject group than in the control group, depending on the definition used for comorbidity. Diseases that occurred more often in the subject group than in the controls were locomotive diseases, insomnia, sinusitis, migraine, depression, stomach/duodenal ulcers and cancer.

This study focussed on subjects with a chronic airway obstruction, which includes both COPD patients and patients with chronic asthma. The reason for not restricting our study population to COPD patients alone is that there is an important clinical overlap between COPD and asthma in elderly patients. Patients with a chronic airway obstruction who are older than 40 are thus a relevant group for the clinical practice, especially for general practitioners who most often have limited diagnostic facilities. We therefore selected subjects with a registered diagnosis of COPD as well as subjects with a registered diagnosis of asthma for this study. On the basis of lung function data we excluded subjects without an airway obstruction (treated or inactive asthma) and subjects with a reversible airway obstruction (51\%) from the subject group.

There were some limitations of this study that need to be mentioned. First, no lung function testing was performed in the control group. It is therefore possible that some controls also had airway disease. 
Manen, J.G. van, Bindels, P.J.E., Ijzermans, C.J>, Zee, J.S. van der, Bottema, B.J.A.M., Schadé, E.

Prevalence of comorbidity in patients with a chronic airway obstruction and controls over the age of 40 .

Journal of Clinical Epidemiology: 54, 2001, nr. 3, p. 287-293

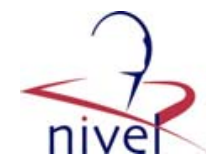

However, in all cases both the general practitioner and the participant in the control group said that there was no diagnosis of asthma or COPD. Moreover, a large community study in the Netherlands had previously shown that patients with an $\mathrm{FEV}_{1}<90 \%$ and respiratory symptoms were almost all known to the general practitioner [8]. Only two out of one-thousand individuals turned out to have airway disease that was unknown to their GP according to these criteria. This corresponds to one patient with undetected airway disease in our control group. Still, milder types of airway disease may have been present in the control group. Yet as this study focussed on subjects with a chronic airway obstruction, this probably has been of little importance for our results.

A second limitation of the study may be that a high proportion of eligible subjects dropped out in comparison with the control group. This response may have been influenced by the lung function testing these subjects had to undergo. As a result, individuals with a comparatively worse state of health in the subject group may have dropped out relatively more often than individuals in the control group. This may have caused an underestimation of the prevalence of comorbidity in the subject group. The true differences in prevalence between subject and control group may have been even higher.

A third limitation of the study may be that the results were based on a subjective measure of comorbidity, namely the self-report of patients. Several studies have indicated that patients' selfreports are generally fairly accurate [9-11]. However, for some diseases agreement between a questionnaire data and medical record data is rather poor, such as in the case of locomotive diseases $[9,10]$. These diseases may reflect a symptom rather than a physician-diagnosed disease. The data on these diseases should therefore be interpreted as such. Nevertheless, these data are expected to be valid for assessing the symptom rather than the diagnosis, because patients are considered to be the best experts in reporting perceived disease symptoms. Moreover, as misclassification of diseases is probably similar in the subject and the control group, the differences in prevalence between these groups will not have been affected. Similarly, the risk of having a disease represented by the odds ratios will not have been affected.

The high prevalence we found in our study for high blood pressure and heart disease was comparable in the two groups. Although these diseases are important for the clinical practice because of the high prevalence, they seem to be unrelated to chronic airway obstruction. Consistent with the literature, we found that heart diseases were more common among both the elderly and men [1].

The prevalence of locomotive diseases, insomnia, sinusitis, migraine, depression, stomach/duodenal ulcers and cancer was significantly higher in the subject group than in the control group. The high prevalence of locomotive diseases is difficult to explain, but may be related to a lack of physical exercise in the subject group. Stomach or duodenal ulcers and cancer may have been more common in the subject group because most of them (90\%) were current or past smokers [12]. The percentage of smokers in the general Dutch population was much lower in 1997, namely $36 \%$ for individuals of 45 to 64 years of age and $21 \%$ for individuals older than 64 [13]. Although we have no information on smoking history in our control group (a random sample of the general practice population), there is no reason to suggest that their smoking behavior differs from the general Dutch population. The high prevalence of ulcers may also have resulted from the subjects' use of lung medication such as oral corticosteroids [14]. Sinusitis may have been more common in the subject group, as it may be associated with the inflammatory process in the airway system. Insomnia may also have been more common in the subject group as this group might suffer from breathlessness during the night. The higher prevalence of depression we found among subjects has also been mentioned in the literature $[6,15]$.

An unexpected finding was that the prevalence of hypertension, heart disease and stroke, which are also related to smoking, were not higher in the subject group than in the control group. This may be due to the fact that the risk of death due to cardiovascular disease is much higher among subjects with ventilatory impairment than among subjects without ventilatory impairment [16]. As a result, a relatively high proportion of subjects with a chronic airway obstruction who also had cardiovascular disease may have died, subsequently causing a decrease in the prevalence of cardiovascular diseases in subjects with a chronic airway obstruction.

In conclusion, most patients with a chronic airway obstruction, especially older patients, suffer from other diseases and have a higher risk of diseases than controls. Therefore, the effect of other diseases 
Manen, J.G. van, Bindels, P.J.E., Ijzermans, C.J>, Zee, J.S. van der, Bottema, B.J.A.M., Schadé, E.

Prevalence of comorbidity in patients with a chronic airway obstruction and controls over the age of 40 .

Journal of Clinical Epidemiology: 54, 2001, nr. 3, p. 287-293

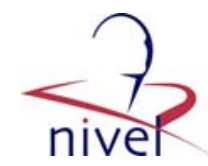

should be considered when treating a patient with a chronic airway obstruction and when discussing the consequences and prognosis of the disease. Excluding patients with comorbidity in clinical research, which is common practice, may severely limit the external validity. Of course, the extent to which the external validity is limited depends on which patients with which comorbid diseases are excluded. For example, the external validity is severely limited in a study conducted in elderly COPD patients that excludes patients with all kinds of comorbidity, while the external validity is hardly limited in a study conducted in middle-aged COPD patients from which only subjects with heart disease are excluded. Studies including patients with comorbidity should adjust for the potential confounding influence of comorbidity on outcome variables. This is particularly true for diseases that occur more frequently in the subject group than in the control group, such as locomotive diseases, insomnia, sinusitis, migraine, depression, stomach/duodenal ulcer and cancer.

\section{ACKNOWLEDGMENTS}

The authors are grateful to C.M. Roos for interpreting the lung function results. This study was supported by Boehringer Ingelheim NL by supplying all materials and personnel for the lung function testing.

\section{TABLES}

Table 1

Characteristics of subjects and controls

\begin{tabular}{|c|c|c|c|}
\hline Characteristic & Subjects $^{\mathrm{a}}(n=290)$ & Controls $(n=421)$ & $\begin{array}{l}\mathrm{P} \text {-value } \\
\chi^{2} \text {-test } / t \text {-test }\end{array}$ \\
\hline Male & $186(64.1)$ & $172(41.1)$ & $<0.001$ \\
\hline Age & $65.8(10.9)$ & $65.9(12.5)$ & ns \\
\hline Low education level & $242(86.1)$ & $314(79.5)$ & 0.03 \\
\hline DNHS ${ }^{b}$ insurance & $231(79.9)$ & $284(67.9)$ & $<0.001$ \\
\hline Living alone & $75(25.9)$ & $107(25.8)$ & ns \\
\hline $\mathrm{FEV}_{1}>70 \%$ predicted & $149(51.4)$ & - & - \\
\hline $\mathrm{FEV}_{1} 50-70$ predicted & $78(26.9)$ & - & \\
\hline $\mathrm{FEV}_{1}<50 \%$ predicted & $63(21.7)$ & - & \\
\hline $\mathrm{FEV}_{1}$ reversibility $\leqslant 12 \%$ & $217(74.8)$ & - & - \\
\hline
\end{tabular}

Data are expressed as numbers (\%) or mean (SD).

${ }^{\mathrm{a}} \mathrm{FEV}_{1} / \mathrm{VC}$ before and after salbutamol $<$ predicted $-1.64 \times \mathrm{SD}$.

${ }^{b}$ Dutch National Health Service.

Table 2

Prevalence of comorbidity in subjects and controls

\begin{tabular}{|c|c|c|c|c|c|c|c|c|c|c|}
\hline \multirow[b]{3}{*}{ Number of diseases } & \multicolumn{5}{|c|}{ All diseases } & \multicolumn{5}{|c|}{$\begin{array}{l}\text { Diseases for which participants used medication or contacted } \\
\text { a doctor }\end{array}$} \\
\hline & \multicolumn{2}{|c|}{$\begin{array}{l}\text { Subjects } \\
(n=265)\end{array}$} & \multicolumn{2}{|c|}{$\begin{array}{l}\text { Controls } \\
(n=364)\end{array}$} & \multirow{2}{*}{$\begin{array}{l}\text { Adjusted }{ }^{b} \text { odds ratio } \\
\text { OR }(95 \% \mathrm{CI})\end{array}$} & \multicolumn{2}{|c|}{$\begin{array}{l}\text { Subjects } \\
(n=265)\end{array}$} & \multicolumn{2}{|c|}{$\begin{array}{l}\text { Controls } \\
(n=364)\end{array}$} & \multirow{2}{*}{$\begin{array}{l}\text { Adjusted }{ }^{b} \text { odds odds ratio } \\
\text { OR }(95 \% \mathrm{CI})\end{array}$} \\
\hline & $n$ & $(\%)$ & $n$ & $(\%)$ & & $n$ & $(\%)$ & $n$ & $(\%)$ & \\
\hline 0 & 71 & $(26.8)$ & 135 & $(37.1)$ & $1.60(1.10-2.33)$ & 100 & $(37.7)$ & 180 & $(49.5)$ & $1.56(1.10-2.20)$ \\
\hline$\geqslant 1$ & 194 & $(73.2)$ & 229 & $(62.9)$ & & 165 & $(62.3)$ & 184 & $(50.5)$ & \\
\hline 0 & 71 & & 135 & & - & 100 & & 180 & & - \\
\hline $1-2$ & 134 & $(50.6)$ & 189 & $(51.9)$ & & 135 & $(50.9)$ & 162 & $(44.5)$ & \\
\hline $3-4$ & 42 & (15.8) & 32 & $(8.8)$ & & 21 & $(7.9)$ & 16 & (4.4) & \\
\hline$\geqslant 5$ & 18 & $(6.8)$ & 8 & (2.2) & & 9 & (3.4) & 6 & (1.6) & \\
\hline
\end{tabular}

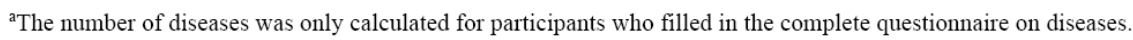

${ }^{b}$ The control group is the reference group, odds ratios are adjusted for gender, education and insurance. 
Manen, J.G. van, Bindels, P.J.E., Ijzermans, C.J>, Zee, J.S. van der, Bottema, B.J.A.M.,

Schadé, E.

Prevalence of comorbidity in patients with a chronic airway obstruction and controls over the age of 40 .

Journal of Clinical Epidemiology: 54, 2001, nr. 3, p. 287-293

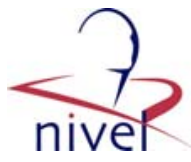

Table 3

Prevalence of specific diseases in subjects and controls and results of logistic regression

\begin{tabular}{|c|c|c|c|c|c|c|c|c|}
\hline \multirow[b]{2}{*}{ Diseases } & \multicolumn{3}{|c|}{ Subjects $(n=290)$} & \multicolumn{3}{|c|}{ Controls $(n=421)$} & \multicolumn{2}{|c|}{ Adjusted odds ratios ${ }^{\mathrm{a}}$} \\
\hline & $n$ & $(\%)$ & Ranking & $n$ & $(\%)$ & Ranking & OR & $(95 \% \mathrm{CI})$ \\
\hline Locomotive diseases & 104 & $(36.1)^{*}$ & 1 & 116 & $(28.6)$ & 1 & 1.55 & $(1.09-2.20)$ \\
\hline High blood pressure & 65 & $(22.7)$ & 2 & 87 & (21.4) & 2 & & \\
\hline Insomnia & 50 & $(17.3)^{*}$ & 3 & 46 & $(11.3)$ & 3 & 1.65 & $(1.04-2.62)$ \\
\hline Heart disease & 38 & $(13.1)$ & 4 & 45 & $(11.0)$ & 4 & & \\
\hline Sinusitis & 36 & $(12.4)^{*}$ & 5 & 10 & $(2.5)$ & 14 & 6.08 & $(2.87-12.89)$ \\
\hline Migraine & 29 & $(10.0)^{*}$ & 6 & 17 & $(4.2)$ & 9 & 3.13 & $(1.60-6.13)$ \\
\hline Depression & 25 & $(8.7)^{*}$ & 7 & 18 & (4.4) & 8 & 2.10 & $(1.07-4.11)$ \\
\hline Dizziness & 21 & $(7.3)$ & 9 & 20 & (4.9) & 6 & & \\
\hline Ulcer stomach/duodenum & 21 & $(7.2)^{*}$ & 8 & 6 & (1.5) & 20 & 7.33 & $(2.41-22.25)$ \\
\hline Cancer & 18 & $(6.2)^{*}$ & 10 & 10 & $(2.5)$ & 15 & 2.47 & $(1.06-5.78)$ \\
\hline Atherosclerosis & 16 & $(5.5)^{*}$ & 11 & 7 & (1.7) & 17 & & \\
\hline Thyroid diseases & 14 & $(4.9)$ & 12 & 19 & $(4.7)$ & 7 & & \\
\hline Diabetes & 13 & $(4.5)$ & 13 & 29 & $(7.1)$ & 5 & & \\
\hline Intestinal diseases & 12 & $(4.2)$ & 14 & 12 & (2.9) & 12 & & \\
\hline Skin diseases & 12 & $(4.2)$ & 15 & 10 & $(2.5)$ & 16 & & \\
\hline Gall bladder diseases & 11 & (3.8) & 16 & 7 & (1.7) & 18 & & \\
\hline Stroke & 9 & (3.1) & 17 & 15 & (3.7) & 10 & & \\
\hline Chronic cystitis & 9 & (3.1) & 18 & 7 & (1.7) & 19 & & \\
\hline Kidney stones & 8 & $(2.8)$ & 19 & 12 & (2.9) & 13 & & \\
\hline Thrombosis & 7 & (2.4) & 20 & 13 & (3.2) & 11 & & \\
\hline Epilepsy & 4 & (1.4) & 21 & 4 & $(1.0)$ & 21 & & \\
\hline Liver diseases & 1 & $(0.3)$ & 22 & 2 & $(0.5)$ & 22 & & \\
\hline Renal diseases & 1 & $(0.3)$ & 23 & 1 & $(0.2)$ & 23 & & \\
\hline
\end{tabular}

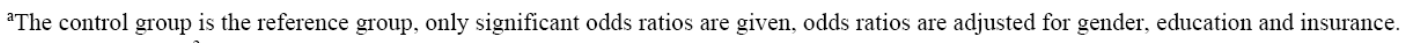
$*$ P-value $<0.05\left(\chi^{2}\right.$-test, subject/control $\times$ disease present/absent $)$.

Table 4

Prevalence of $\geqslant 1$ disease and of the most common diseases in subgroups of subjects with a chronic airway obstruction

\begin{tabular}{|c|c|c|c|c|c|c|c|c|c|c|c|c|}
\hline & \multicolumn{2}{|c|}{ Male $(n=186)$} & \multicolumn{2}{|c|}{$\begin{array}{l}\text { Female } \\
(n=104)\end{array}$} & \multicolumn{2}{|c|}{$\begin{array}{l}\mathrm{FEV}_{1}<50 \% \\
\operatorname{pred}(n=63)\end{array}$} & \multicolumn{2}{|c|}{$\begin{array}{l}\mathrm{FEV}_{1} 50-70 \% \\
(n=78)\end{array}$} & \multicolumn{2}{|c|}{$\begin{array}{l}\mathrm{FEV}_{1}>70 \% \\
\operatorname{pred}(n=149)\end{array}$} & & \\
\hline & $n$ & $(\%)$ & $n$ & $(\%)$ & $n$ & $(\%)$ & $n$ & $(\%)$ & $n$ & $(\%)$ & & \\
\hline$\geqslant 1$ disease $^{a}$ & 123 & $(72.4)$ & 71 & $(74.7)$ & 41 & $(70.7)$ & 52 & $(75.4)$ & 101 & $(73.2)$ & & \\
\hline Locomotive diseases & 54 & $(29.3)^{*}$ & 50 & $(48.1)$ & 17 & $(27.0)$ & 29 & $(37.7)$ & 58 & $(39.2)$ & & \\
\hline High blood pressure & 38 & $(20.8)$ & 27 & $(26.2)$ & 9 & $(14.8)$ & 21 & $(27.3)$ & 35 & $(23.6)$ & & \\
\hline Insomnia & 26 & $(14.0)^{*}$ & 24 & $(23.3)$ & 12 & (19.4) & 9 & $(11.5)$ & 29 & $(19.5)$ & & \\
\hline Heart disease & 30 & $(16.2)^{*}$ & 8 & $(7.7)$ & 9 & $(14.3)$ & 13 & $(16.9)$ & 16 & (10.7) & & \\
\hline Sinusitis & 19 & $(10.2)$ & 17 & $(16.3)$ & 6 & $(9.5)^{*}$ & 4 & $(5.1)$ & 26 & (17.4) & & \\
\hline Migraine & 12 & $(6.5)^{*}$ & 17 & $(16.3)$ & 4 & $(6.3)$ & 6 & $(7.7)$ & 19 & $(12.8)$ & & \\
\hline Depression & 12 & $(6.5)$ & 13 & $(12.6)$ & 1 & $(1.6)^{*}$ & 5 & $(6.5)$ & 19 & $(12.8)$ & & \\
\hline Dizziness & 13 & $(7.1)$ & 8 & $(7.7)$ & 1 & $(1.6)$ & 7 & $(9.0)$ & 13 & (8.8) & & \\
\hline Ulcer stomach/duodenum & 13 & $(7.0)$ & 8 & $(7.7)$ & 5 & $(7.9)$ & 6 & $(7.7)$ & 10 & $(6.7)$ & & \\
\hline Cancer & 13 & $(7.0)$ & 5 & $(4.8)$ & 4 & (6.3) & 7 & $(9.0)$ & 7 & $(4.7)$ & & \\
\hline \multirow[t]{3}{*}{ Atherosclerosis } & 10 & $(5.4)$ & 6 & $(5.8)$ & 1 & (1.6) & 5 & (6.4) & 10 & (6.8) & & \\
\hline & \multicolumn{2}{|c|}{$\begin{array}{l}40-55 \text { yrs. } \\
(n=50)\end{array}$} & \multicolumn{2}{|c|}{$\begin{array}{l}55-70 \text { yrs. } \\
(n=118)\end{array}$} & \multicolumn{2}{|c|}{$\begin{array}{l}>70 \text { yrs. } \\
(n=118)\end{array}$} & \multicolumn{2}{|c|}{$\begin{array}{l}\text { Never smokers } \\
(n=27)\end{array}$} & \multicolumn{2}{|c|}{$\begin{array}{l}\text { Past smokers }{ }^{\mathrm{b}} \\
(n=103)\end{array}$} & \multicolumn{2}{|c|}{$\begin{array}{l}\text { Smokers }^{\mathrm{b}} \\
(n=159)\end{array}$} \\
\hline & $n$ & $(\%)$ & $n$ & $(\%)$ & $n$ & $(\%)$ & $n$ & $(\%)$ & $n$ & $(\%)$ & $n$ & $(\%)$ \\
\hline$\geqslant$ disease $^{\mathrm{a}}$ & 29 & $(60.4)^{*}$ & 73 & $(69.5)$ & 89 & $(82.4)$ & 15 & $(62.5)$ & 73 & $(77.7)$ & 105 & $(71.9)$ \\
\hline Locomotive diseases & 13 & $(26.0)$ & 44 & $(37.6)$ & 45 & $(38.5)$ & 6 & $(22.2)$ & 38 & $(37.6)$ & 59 & $(37.1)$ \\
\hline High blood pressure & 3 & $(6.0)^{*}$ & 27 & $(23.5)$ & 34 & $(29.1)$ & 7 & $(25.9)$ & 29 & $(28.2)$ & 29 & $(18.7)$ \\
\hline Insomnia & 12 & $(24.0)$ & 21 & (17.9) & 17 & (14.4) & 5 & $(18.5)$ & 13 & $(12.6)$ & 31 & (19.6) \\
\hline Heart disease & 1 & $(2.0)^{*}$ & 16 & (13.7) & 21 & $(17.8)$ & 1 & $(3.7)$ & 17 & (16.5) & 20 & $(12.7)$ \\
\hline Sinusitis & 12 & $(24.0)^{*}$ & 11 & (9.3) & 12 & $(10.2)$ & 3 & $(11.1)$ & 14 & (13.6) & 18 & (11.3) \\
\hline Migraine & 11 & $(22.0)^{*}$ & 9 & $(7.6)$ & 9 & $(7.7)$ & 7 & $(25.9)^{*}$ & 6 & $(5.9)$ & 16 & $(10.1)$ \\
\hline Depression & 10 & $(20.0)^{*}$ & 8 & (6.8) & 6 & $(5.1)$ & 2 & $(7.4)$ & 8 & $(7.8)$ & 15 & $(9.5)$ \\
\hline Dizziness & 5 & $(10.0)^{*}$ & 3 & (2.6) & 13 & $(11.1)$ & 0 & & 7 & $(6.9)$ & 14 & $(8.9)$ \\
\hline Ulcer stomach/duodenum & 3 & $(6.0)$ & 9 & $(7.6)$ & 9 & $(7.6)$ & 1 & $(3.7)$ & 15 & (4.9) & 15 & (9.4) \\
\hline Cancer & 1 & $(2.0)$ & 4 & (3.4) & 11 & (9.3) & 0 & & 8 & (7.8) & 10 & (6.3) \\
\hline Atherosclerosis & 2 & (4.1) & 5 & $(4.2)$ & 9 & $(7.6)$ & 0 & $(0.0)$ & 3 & $(2.9)$ & 13 & $(8.2)$ \\
\hline
\end{tabular}

*P-value $<0.05\left(\chi^{2}\right.$-test, disease present/absent $\times$ e.g. male/female $)$.

$a \geqslant 1$ diseases was only calculated for subjects who filled in the complete questionnaire on diseases.

${ }^{b}$ Past smokers were defined as individuals who had stopped smoking for more than 5 years; smokers were defined as current smokers or as individuals who had stopped smoking for less than 5 years. 
Manen, J.G. van, Bindels, P.J.E., Ijzermans, C.J>, Zee, J.S. van der, Bottema, B.J.A.M., Schadé, E.

Prevalence of comorbidity in patients with a chronic airway obstruction and controls over the age of 40 .

Journal of Clinical Epidemiology: 54, 2001, nr. 3, p. 287-293

\section{REFERENCES}

1. Verbrugge LM, Patrick DL. Seven chronic conditions: their impact on US adults' activity levels and use of medical services. Am J Public Health 1995;85:173-82.

2. Ferrer M, Alonso J, Morera J, Marrades RM, Khalaf A, Aguar MC, Plaza V, Prieto L, Anto JM. Chronic obstructive pulmonary disease stage and health-related quality of life. The Quality of Life of Chronic Obstructive Pulmonary Disease Study Group. Ann Intern Med 1997; 127:1072-9.

3. Schellevis FG, Van de Lisdonk EH, van der Velden J, Hoogbergen SHJL, Van Eijk JTM, van Weel $\mathrm{C}$. Consultation rates and incidence of intercurrent morbidity among patients with chronic disease in general practice. Br J Gen Pract 1994;44:259-62.

4. Petty TL. Lung cancer and chronic obstructive pulmonary disease. Med Clin N Am 1996;80:645-55.

5. Venuta F, Rendina EA, Pescarmona EO, De Giacomo T, Vizza D, Flaishman I, Ricci C. Occult lung cancer in patients with bullous emphysema. Thorax 1997;52:289-90.

6. Isoaho R, Keistinen T, Laippala P, Kivela SL. Chronic obstructive pulmonary disease and symptoms related to depression in elderly persons. Psychol Rep 1995;76:287-97.

7. Statistics Netherlands. Netherlands Health Interview Survey 1981- 1991. The Hague: SDU publishers/CBS-publications, 1992.

8. Tirimanna PRS, Van Schayck CP, Den Otter JJ, van Weel C, Van Herwaarden CLA, van den Boom G, Van Grunsven PM, Van den Bosch WJHM. Prevalence of asthma and COPD in general practice in 1992: has it changed since 1977? Br J Gen Pract 1996;46:277-81.

9. Haapanen N, Miilunpalo S, Pasanen M, Oja P, Vuori I. Agreement between questionnaire data and medical records of chronic diseases in middle-aged and elderly Finnish men and women. Am J Epidemiol 1997;145:762-9.

10. Kriegsman DM, Penninx W, van Eijk JT, Boeke AJ, Deeg DJ. Selfreports and general practitioner information on the presence of chronic diseases in community dwelling elderly. A study on the accuracy of patients' self-reports and on determinants of inaccuracy. J Clin Epidemiol 1996;49:1407-17.

11. Katz JN, Chang LC, Sangha O, Fossel AH, Bates DW. Can comorbidity be measured by questionnaire rather than medical record review? Med Care 1996;34:73-84.

12. Bernersen B, Johnsen R, Straume B. Non-ulcer dyspepsia and peptic ulcer: the distribution in a population and their relation to risk factors. Gut 1996;38:822-5.

13. Statistics Netherlands, Ministry of Health, Welfare and Sports. Vademecum of health statistics of the Netherlands 1998. The Hague: sdu publishers/CBS-publications, 1998.

14. Pecora PG, Kaplan B. Corticosteroids and ulcers: is there an associations? Ann Pharmacotherapy 1996;30:870-2.

15. Curtis JR, Deyo RA, Hudson LD. Pulmonary rehabilitation in chronic respiratory insufficiency. 7. Health-related quality of life among patients with chronic obstructive pulmonary disease. Thorax 1994;49: 162-70.

16. Tockman MS, Comstock GW. Respiratory risk factors and mortality: longitudinal studies in Washington County, Maryland. Am Rev Res Dis 1989;140:S56-63. 